\title{
Randomized Questionnaire Based Case-Control Research Study on Evaluation of Sexual Function in Indian Patients Taking Oral Finasteride for Androgenetic Alopecia
}

\author{
C.R.V. Narasimhalu
}

To view enhanced content go to www.dermtherapy-open.com Received: August 22, 2015 / Published online: October 5, 2015

(C) The Author(s) 2015. This article is published with open access at Springerlink.com

\section{ABSTRACT}

Introduction: Finasteride is one of the most common drugs used in androgenetic alopecia. The literature discusses the sexual side effects of the drug; however, in practice there is little evidence to support this. The aim of the present study was to investigate the sexual dysfunction in patients taking finasteride $1 \mathrm{mg}$ for androgenetic alopecia.

Methods: A questionnaire, based on the International Index of Erectile Function, was given to approximately 586 patients with androgenetic alopecia who were being treated with finasteride $1 \mathrm{mg}$ for an average of 16 weeks. These patients were compared to an age-related control group who were attending the Dermatology Out Patients Department for

Electronic supplementary material The online version of this article (doi:10.1007/s13555-015-0084-3) contains supplementary material, which is available to authorized users.

C.R.V.Narasimhalu ( $\square)$

Department of Skin and STD, Saveetha Medical

College, Saveetha University, Saveetha Nagar,

Thandalam, Kancheepuram, Tamil Nadu 602105,

India

e-mail: drnarasimhalu@saiskinclinic.in various other skin ailments not related to hair disorders.

Results: Statistical analysis of the results showed no significant difference in the scores between patients taking finasteride and the control group.

Conclusion: Analysis showed no significant difference in sex-related problems with that of patients taking finasteride and age matched controls, suggesting that sex-related issues are not a side effect of finasteride.

Keywords: Androgenetic alopecia; Erectile dysfunction; Finasteride; Loss of libido; Male pattern baldness

\section{INTRODUCTION}

Finasteride $1 \mathrm{mg}$ is used successfully all over the world for the treatment of androgenetic alopecia in male pattern baldness [1]. It is approved in the USA and many other countries. Various clinical trials have established finasteride's efficacy in adult men with predominant vertex, anterior and midscalp region $[2,3]$. On average, less than $2 \%$ of patients show side effects to the drug [4]. Common side effects are loss of libido, erectile 
dysfunction and decreased ejaculate volume. These side effects were found in less than $0.5 \%$ of patients [11].

To assess the huge difference $[2,11]$ in reporting the side effects, we conducted a 2-year randomized, questionnaire-based research study on patients receiving finasteride $1 \mathrm{mg}$ tablets for androgenetic alopecia. For this, we used a questionnaire based on the International Index of Erectile Function (IIEF) (Supplementary Table 1) [5]. This checks five domains: erectile function, orgasmic function, sexual desire, intercourse satisfaction and overall sexual satisfaction. A higher IIEF score indicates better sexual function and low score (below 25) indicates erectile dysfunction.

The aim of the present study was to evaluate an age-matched comparison and evaluation of sexual function in patients treated by finasteride $1 \mathrm{mg}$ for early androgenetic alopecia by using IIEF.

\section{METHODS}

We randomized approximately 586 subjects in a simple random sampling method. Inclusion criteria were age 18-40 years, who came for an outpatient consultation for male pattern androgenetic alopecia, which was diagnosed using the Norwood-Hamilton's grading of male pattern alopecia with grade 3 to 5 on treatment with finasteride $1 \mathrm{mg}$, with good physical health. Exclusion criteria were patients being treated for various other causes of hair loss other than androgenetic alopecia. Those selected patients were briefed about the IIEF questionnaire and, with their consent, the questionnaire was provided for completion. A mean duration of approximately 16 weeks of medication was consumed by the patients at the time of answering the questionnaire. Our controls were 586 patients who attended outpatient consultation for various other non-hair related diseases such as Psoriasis vulgaris, Lichen planus, allergic contact dermatitis, irritant contact dermatitis, nail disorders, etc.

The resultant scores of erectile function domain and IIEF domain of both the study group taking Finasteride $1 \mathrm{mg}$ and their age-wise control group were analyzed with the IBM Software package (SPSS Statistics, NY, USA).

All procedures followed were in accordance with the ethical standards of the responsible committee on human experimentation (institutional and national) and with the Helsinki Declaration of 1964, as revised in 2013. Informed consent was obtained from all patients for being included in the study.

\section{RESULTS}

Both the study group and controls were asked to answer the IIEF questionnaire anonymously to avoid any identity on sexual weakness. The

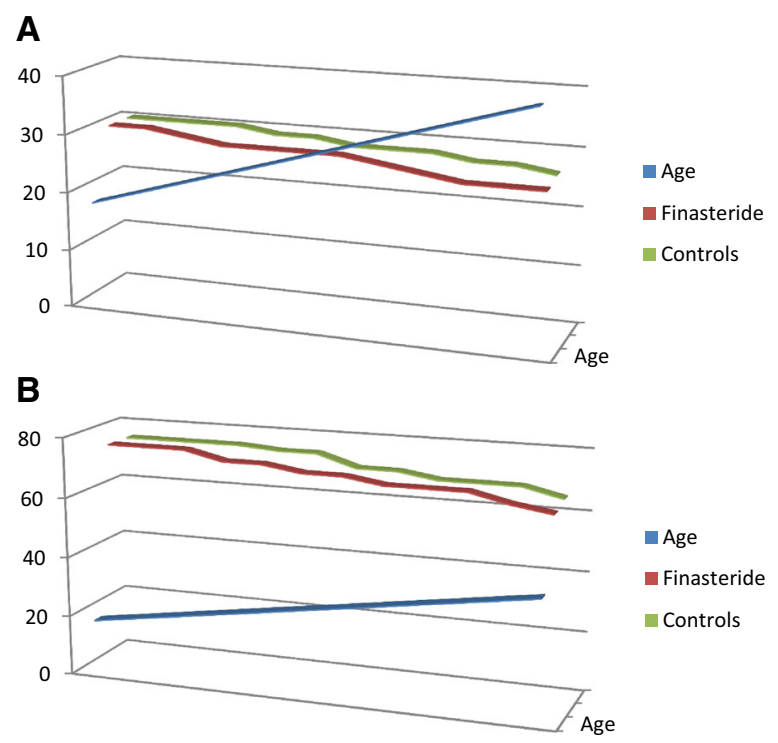

Fig. 1 Age controlled 3D graphs showing the scores of domain in erectile function (a) and international index of erectile function domain (b) in patients on Finasteride and their controls with age and scores both depicted in $\mathrm{Y}$ axis 
results were compared in an age-wise manner. Comparing the age-wise finasteride-consuming patients and the control group, there was no statistical difference between the groups regarding their sexual function in total IIEF score or in any of the five domains mentioned.

The age-controlled graphs (Fig. 1) show the scores in the erectile function domain (A) and international index of erectile function domain (B) in patients on finasteride and their controls.

\section{DISCUSSION}

The main mechanism in androgenetic alopecia is miniaturization of hair follicles from terminal to vellus hair [6] due to the effect of androgen, especially dihydrotestosterone. Testosterone is converted by 5 alpha reductase to 5 alpha dihydrotestosterone, which is five times more potent than testosterone [8]. This dihydrotestosterone binds to the androgen receptors of the genetically marked hair follicle and leads to miniaturization of that hair follicle. This also reduces the rate of hair growth [7].

Finasteride is an azasteroid type 2 isoenzyme, 5 alpha reductase inhibitor, which inhibits dihydrotestosterone conversion from testosterone [8]. This type 2 isoenzyme is present in the hair follicles and its activity is important in controlling the end organ hyper-reactivity causing androgenetic alopecia [8]. Testosterone is responsible for sexual function after puberty, but not by dihydrotestosterone. Observation of eunuchs and prepubertal boys highlighted the role of testosterone in the induction of androgenetic alopecia [9]. Therefore, it is evident that finasteride should not cause any side effects, relating to sexual health, as there will be no decrease in the quantity or quality of the testosterone level. However, clinical trials conducted by Leyden et al. [10] and Kaufman et al. [2] resulted in $2 \%$ of patients experiencing sexual side effects such as the loss of libido, erectile dysfunction and decreased ejaculate volume [4].

In this study, patients taking Finasteride $1 \mathrm{mg}$ for androgenetic alopecia and the control group were provided with the IIEF questionnaire and their responses analyzed. The results indicated that erectile and sexual function was not reduced compared to the controls. So, not only theoretically, finasteride was found to be a comparatively safe drug in this Indian male population. This study was conducted in the Indian context on the basis of the IIEF [5] and the European study by Tosti et al. [11]. The present study was limited to Indian patients. Further studies should be conducted in a multi-center, double-blind manner.

\section{CONCLUSION}

In both our study and the study conducted by Tosti et al. [11], sexual and erectile function of those subjects who were orally treated with finasteride was not reduced compared with their age-related controls.

\section{ACKNOWLEDGMENTS}

No funding or sponsorship was received for this study or publication of this article. All named authors meet the International Committee of Medical Journal Editors (ICMJE) criteria for authorship for this manuscript, take responsibility for the integrity of the work as a whole, and have given final approval for the version to be published. 
Disclosures. C. R. V. Narasimhalu has nothing to disclose.

\section{Compliance with ethics guidelines. All} procedures followed were in accordance with the ethical standards of the responsible committee on human experimentation (institutional and national) and with the Helsinki Declaration of 1964, as revised in 2013. Informed consent was obtained from all patients for being included in the study.

Open Access. This article is distributed under the terms of the Creative Commons Attribution-NonCommercial 4.0 International License (http://creativecommons.org/licenses/ by-nc/4.0/), which permits any noncommercial use, distribution, and reproduction in any medium, provided you give appropriate credit to the original author(s) and the source, provide a link to the Creative Commons license, and indicate if changes were made.

\section{REFERENCES}

1. Roberts JL, Fielder V, Imperato-McGinley J, et al. Clinical dose ranging studies with Finasteride, a type 25 alpha reductase. J Am Acad Dermatol. 1999;40:930-7.

2. Kaufman KD, Olsean EA, Whiting D, et al. Finasteride in the treatment of man with androgenetic alopecia. J Am Acad Dermatol. 1998;39:578-9.

3. Brenner S, Matz H. Improvement in androgenic alopecia in 53-76 years old men using oral Finasteride. Int J Dermatol. 1999;38:928-30.

4. Arndt KA, Hsu JTS. Manual of dermatologic therapeutics. 7th ed. Lippincott Williams \& Wilkins; p. 339-40.

5. Rosen RC, Riley A, Wagner G, Osterloh IH, Kirkpatrick J, Mishra A. The international index of erectile function (IIEF) a multidimensional scale for assessment of erectile dysfunction. Urology. 1997;49(6):822-30.

6. Kligman AM. The comparative histopathology of male pattern baldness and senescent baldness. In: De Villez RL, editor. Clinics in dermatology. Philadelphia: Lippincot; 1998. p. 108-13.

7. Hoffmann R, Van Neste D. Recent findings with computerized methods for scalp hair growth measurements. J Invest Dermatol Symp Proc. 2005;10:285-8.

8. RG Valia, Valia AR, editors. IADVL textbook of dermatology, vol 1. 3rd ed. p. 894.

9. Hamilton JB. Male hormone stimulation is prerequisite and an incitement in common baldness. Am J Anat. 1942;71:451-60.

10. Leyden J, Dunlap F, Miller B, et al. Finasteride in the treatment of men with frontal male pattern hair loss. J Am Acad Dermatol. 1999;40:930-7.

11. Tosti A, Piraccini BM, Soli M. Evaluvation of sexual function in subjects taking finasteride for the treatment of androgenic alopecia. J Eur Acad Dermatol Venereol. 2001;15:418-21. 